\title{
Clinical damage, medical monopoly, the expropriation of health: Three dimensions of iatrogenic tort
}

\author{
Ivan Illich Centro Intercultural de Documentacion, Cuernavaca, Mexico
}

I begin by saying that I am not a doctor; I have no clinical experience. I am a philosopher. I must therefore ask myself what I am talking about. I am speaking in some way related to health. I find out that health is, as far as I can understand, an ordinary language word referring to what theoretical biologists would call 'the level of autonomy with which an organism adapts its internal states to the conditions of the environment, and ... (in the case of human health) consciously engages in changing some of these conditions in order to make adaptation more pleasurable or more effective.' Health therefore refers to something which is a property of aliveness it is related to the aliveness of that organism or of that primary group.

Health care can mean two things: an increase in this autonomy, or, and that is a very strange way of using the concept of health care, substituting for the autonomous ability to cope with changing environments and changing, decaying perhaps, internal states, engineered inputs which adapt that organism to its environment or which render the environment less trivial; decrease the level of noise in the environment and thereby make it supposedly more suitable for that organism.

In thinking about these matters I come, therefore, to the conclusion that (at least if my starting point is not wrong) there must be some level beyond which any further attempt at improving health by transforming autonomous coping into heteronomous maintenance, what I originally called 'health', must decline. I start with a dilemma.

Now I look at the medical endeavour, which is really an engineering endeavour, in order to intervene for individuals who are sick, who might become sick, or in supposedly disease-making aspects of their environment, in order to improve health. Three years ago, I never thought that I would dare to say those things, for me clear simple observations, which now have become evidence. I say that medical endeavour gives decreasing results with increasing manpower, prestige and money invested in technical means, seeking technical effects. And notwithstanding, society is willing to throw ever more resources into this endeavour.

The simplest explanation is that society does not finance medicine primarily because it seeks measurable, verifiable, specific technical results from technical investments but because of certain nontechnical results, certain non-technical effectiveness of the medical establishment. For instance, if somes people consider it a privilege to have a certain kind $b$ of complex operation in a certain kind of society, onewould consider that that society is bad as long as everybody in that society does not have access under similar conditions to the same very complex ando expensive investment. Medical investments will be made in order to foster social equality. This is a positive external of medical investment: it is nop directly related in any way to health. Some of these externals created by medicine clearly have the characteristics of burdens. Medical investment becomes increasingly more expensive. It imposes increasingly more problems on the city planner, or the transportation engineer, on the teachingr establishment in a society, but these are stillo externals, though negative ones.

\section{Health-denying medicine}

Finally, we observe - I observe at least - that increasingly the unwanted, non-technical effects which result from increased investment in medicat technology produce directly health-denying results This is no more a cost, or no more an externa which can be shifted from medicine, for instance onto the education department. This is a paradoxicat counter-product of medicine, a strange effect which. we ought to face at this moment, because it appears to crop up in all other major enterprises in societ. and so far has left us confused because we have nog named it. They are costs, they are externals. Costs are benefits which are shifted from one institution to another, and there are paradoxical counter products which our major institutions produce which no other institution produces, within whic/S this counter-productivity remains locked. I con sider that an institution has become countere productive when its further development removes society from a purpose or a goal for which societ originally had financed, established and organizeep that institution. When the acceleration of traffico becomes increasingly time-consuming, this is a effect which I call 'counter-productivity'. Whe legitimate learning becomes defined as only that which happens in a certain curriculum withip schools and thereby autodidactic learning is des valued, very soon schools serve for training foof specialized incompetents! This is specific counter productivity in the field of education. When med⿳亠口冋 
cine reaches a certain point at which there is serious discussion as to whether its unwanted side effects are in the field of health or not, its healthdenying, health-destroying effects are not more important than its healing effects, then medicine is threatened by counter-productivity.

The reason why I became involved in a study of medicine had nothing to do with helping other people, individuals, to be less sick as individuals. My interest in medicine was brought about entirely by my belief that in the case of medicine I can describe several different types of counter-productivity. I can develop a taxonomy of iatrogenic health-denial and disease which then helps me to develop very similar, almost identical, catalogues by which I can distinguish the different kinds of counterproductivity in traffic, urbanization, food production or educational institutions.

\section{Clinical iatrogenesis}

I suggest that we first focus on the kind of iatrogenesis about which I assume most of the other speakers intend to speak, namely, the clinically verifiable, specific health-denying or diseasemaking effects of specific medical interventions, pathologies known in the classic notation of medicine which are increased through the practice of medicine. These are not my concern and I am not here for the remaining 19 minutes of my paper in order to lose too much time over them, but I wish to focus on them so that it is very clear in what I am personally relatively uninterested. Because I consider it secondary, I consider it a little bit scandalous. I am in agreement with the saying that one should not wash one's dirty linen in public, and this is the dirty linen of doctors - not my business. And third, because I believe that the more we speak about it, the more people will think that that is the issue which makes the iatrogenic impact of medicine important.

I distinguish four categories in clinical iatrogenesis. These are not medical categories; these are the categories which an outsider or a jurist or a philosopher finds. One is malpractice, negligence, professional callousness. These are matters between the doctor and his creator, if he has one, or the doctor and the law. These are matters for which we accuse a doctor or a nurse of guilt. We tell him, 'You are guilty'.

A second category is accidents. Human error or systems break down. Increasingly, we have systems breaking down as medicine becomes more complex. Things which formerly would have been called callousness are now called inefficiency. Things which formerly would have been called lack of training, are now called a lack of engineering or underdevelopment of apparatus, or the need for further research funds! I do not have to tell you of the evidence which exists in certain countries where one out of four or one out of five patients, depending upon whether the hospital is a university hospital or a simple general hospital to which he is admitted, acquires a specific new iatrogenic disease by hospitalization.

The third category is the specific risks which are accepted. I am not saying whether they are acceptable or not. These are the diseases of medical progress inevitably connected with the administration of certain cures or certain diagnostic tools.

And finally, the fourth type of clinical iatrogenic disease, which, for practical purposes I think one should see as clearly separate, is that which $\mathrm{Dr}$ Quentin Young from Chicago calls the damages resulting from the defensive practice of medicine'. This is a matter much more for certain countries, such as the United States, where malpractice suits are so common and where, Young believes, at this moment the major source of iatrogenic, of clinical iatrogenesis is medicine practised in a defensive way in order to protect doctor and hospital against the accusation of malpractice.

What is common to all these four subclasses of clinical iatrogenesis is what has been called 'the paradox of conglomeration'. We specialize functions, thereby we specialize measurements, series of interventions, each one judged by the relative specialist as a success conglomerate on a higher indicator as a loss, as direct counter-productivity in the area of health. When during the rush hour, I add my car to other thousands of cars on the highway, between entrance and exit, which normally would take me only 15 minutes, I might lose 45 minutes. I add 45 minutes to my traffic-related time investment in life, but while I lose half an hour, my presence on that highway has been calculated as creating a loss of at least 50 if not 150 hours to other cars which are on that highway, each a little retarded because of my presence there. Clinical iatrogenesis from this abstract, economic point of view seems to be nothing more exciting than the congestion effect appearing in medicine.

\section{Social iatrogenesis}

I am much more concerned about the iatrogenic effects of the social structure, social behaviour, the social rituals built around the application of medical technology to people who are supposedly sick or who might become sick and to their environment.

I started out with a definition of what health means for me: an ordinary language word to indicate the level of autonomy.

I call 'overmedicalization' a level in a society of intensity of medical care so high that the ability of people to survive depends primarily on inputs from a specialized industry, and at the same time their environment is impoverished; a level of specific health-related devices and tools so that their willingness and intention to take care of their own 
health declines. Overmedicalization or the overexpansion of medicine will be diagnosed in a society when in that society the ability of people to deal on their own or in the primary group and in their natural unspecialized environment with pain, with disease, with incompetence or impairment, and with anguish, particularly the anguish of death, begins to decline thanks to increasing offers of heteronomous professional services in these areas.

Now this non-clinical iatrogenic impact of medical endeavour inevitably has two sides. It has a social side and an intimate structural or symbolic side, if you want to call it so. Socially, overmedicalization manifests itself by architecture changing because of the existence of hospitals. This is the hospitalization of social space; when apartments become such that the young and those to be born and those who are sick or those who are crippled or those who are dying do not fit in there. The medicalization of family structure takes place at the point when dying at home becomes socially inconceivable, when schedules are so arranged and life is so arranged that aging at home becomes increasingly more painful rather than more beautiful, thanks to our progress in scientific knowledge and technology.

\section{Symbolic iatrogenesis}

The medicalization of resources for care of the sick sets in when most of the ordinary devices which our grandparents had at their disposal - useful or not (I am not discussing this aspect) but still used by doctors and very overwhelmingly used - are available only on prescription. But hand in hand with this social transformation of the external environment goes a symbolic transformation, when people live in a society in which the medical establishment is the best financed. You do not live in such a society, I should say, in the United Kingdom. For this reason, Britain at this moment makes the discussion of this issue everywhere in the world so difficult, because people say - in the United States, in Mexico, in India - 'Oh, if we could only reach British levels where for 4.3 per cent of our gross national product we have such marvellous coverage, when in the United States it is already 8.5 per cent of gross national product for much less marvellous coverage.' But I believe these to be marginal issues when in a society medicine becomes one of the structuring major influences on everyday life. In the Unite States, the health conglomerate - the combine of doctors, hospitals and pharmaceutical industries and. their lackey institutions - is the most importan£. economic sector immediately after the American wa industry. Medicine overtook education some five of six years ago. The fact that it has not reached that proportion in Britain does not change the basic facts. When medicine becomes so important? people are from birth to death involved in medicas rituals and the rituals - trivial behaviour which on does not consider really important - have ons purpose, such as one social purpose: that of generating myths, like those concerning the management of pain, 'pain-killing'. Certainly, to some degree medicine can do that from the outside But when the management of pain becomes such $\dot{a}$ prevailing myth that individuals cease to cultivate the culturally given, that is, the art of 'interpretingo pain, the performance by which the pain sensation is transformed into the real life situation, then pain management can very easily increase the level of unmanageable pain in society rather than decrease it. When in a society people begin to believe that abb disease ought to be eliminated, they becomor increasingly less capable of dealing with disease on their own and the threshold for management of autonomous disease decreases. When in a societ the doctor is represented as he who steps between the skeleton, death, and the patient (the very firs picture of this kind I found dates from 1919 and have collected some I 700 pictures over 700 years representing death personalized and the doctor) when the doctor is conceived as he who will save me from death, the anguish of death, the preparation for this anguish all through life, becomes un manageable. This is I call symbolic iatrogenesis.

I am suggesting to you very strongly the necessit to study, while looking at iatrogenesis, not onlo clinical iatrogenesis (which as I have said, I call the 'dirty linen' of your own profession, and is reallp none of my business) but also a much more profound

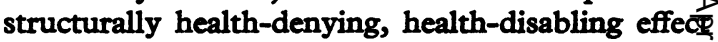
which overgrowth in the medical profession and in medical endeavour inevitably produces in society? This counter-productivity of medicine on a generall level is parallel, is thoroughly consistent with, the्్ paralysis of autonomy and the blockage through internal congestion in most other major productiod agencies in society today. 